\title{
O MOTIVO ÉTICO DO RECURSO À SUBJETIVIDADE TRANSCENDENTAL ${ }^{1}$
}

\author{
Marcelo Fabri (UFSM) ${ }^{2}$
}

fabri.ufsm@gmail.com

Resumo: $\mathrm{O}$ artigo procura investigar o motivo ético que conduziu Husserl à defesa de uma subjetividade transcendental. Em vez de se compreender a atitude fenomenológica como sendo uma abordagem puramente metódica e teórica da subjetividade humana, propõe-se uma interpretação prática da recorrência ao ego transcendental por parte de Husserl. Certo, a fenomenologia sempre começa com a suspensão da atitude natural, mas a possibilidade dessa suspensão envolve um paradoxo: para realizar a neutralização de nossas crenças ligadas à atitude natural, o ego precisa manter sua crença na razão e na ciência. Esta crença será determinante para se compreender o sentido ético da redução transcendental, isto é, a inauguração de uma forma inteiramente nova de vida.

Palavras-chave: Ética; fenomenologia; subjetividade transcendental; redução.

Husserl se preocupou com a ética durante toda a sua trajetória filosófica. Pode-se mesmo dizer que não se trata de um tema secundário no conjunto de sua obra, embora o filósofo seja mais conhecido por suas aspirações teóricometodológicas. Com este trabalho procuramos mostrar que as reflexões de Husserl sobre a razão prática exerceram uma influência fortíssima sobre sua própria ideia de fenomeno-

\footnotetext{
${ }^{1}$ Recebido: 26-08-2015/ Aceito: 03-02-2016/ Publicado on-line: 28-08-2016.

${ }^{2}$ Marcelo Fabri é Professor Associado da Universidade Federal de Santa Maria, Santa Maria, RS, Brasil.
} 
logia transcendental, mais especificamente, queremos sustentar uma tese que, à primeira vista, pode parecer inconsistente: a recorrência à subjetividade transcendental (notável principalmente a partir do primeiro volume das Ideias, de 1913) coincide com uma atitude inevitavelmente prática, aproximando o "giro idealista" de uma problemática essencialmente ética. Se a filosofia deve tornar-se ciência rigorosa, nem por isso a subjetividade humana se define pelo saber que pode conquistar, mas sim pela resolução moral de se conferir um valor ao saber.

Ora, a suspensão de todas as crenças, que caracteriza a epoché, culmina com um paradoxo: tal suspensão implica um ato da vontade caracterizado por uma crença. Como assim? Tudo se passa como se, em Husserl, fosse uma disposição do espírito, e não do entendimento, a nos descobrir como subjetividade transcendental. Se o mundo é produto das atividades de um Eu, isto não se deve à soberania incondicional deste $\mathrm{Eu}$, mas sim a uma unidade inquebrantável: o sujeito é inteligência e poder prático a uma só vez (tese que remonta a Fichte). Certo, a suspensão da crença no mundo abre uma nova região de sentido oferecendo-se a inesgotáveis descrições fenomenológicas (dignas de todo nosso respeito e admiração). No entanto, pensamos ser possível afirmar que a redução não significa apenas como inauguração de um espaço transcendental a ser explorado interminavelmente, mas também, e fundamentalmente, como vinda a si de um sujeito livre sob a forma de vinculação moral ao mundo. Foi, talvez, para garantir e realizar este, por assim dizer, sentido ético do saber e da ciência que Husserl recorreu ao conceito de Ego transcendental. 


\section{A FUNDAÇÃO TEÓRICA DA NORMATIVIDADE E O RECURSO AO SUJEITO}

Comecemos por um argumento que se encontra em Husserl, e que parece desmentir toda afirmação sobre um motivo ético para se recorrer à subjetividade transcendental. Eis o argumento: toda proposição que aspira à verdade, mesmo aquelas que são enunciadas nas situações práticas, já supõe a ideia de máxima perfeição possível em sentido teórico, vale dizer, já aponta para a ideia de Ciência. Assim, diferentemente de todo interesse prático, a Lógica manifesta em nós um interesse essencialmente teórico. Como consequência da proposta de uma Lógica Pura, Husserl anuncia a necessidade de um tratamento formal da razão prática. $\mathrm{O}$ discurso ético deve fundar-se não no impulso de uma subjetividade humana pessoal, mas nas leis axiológicas formais, válidas para todo sujeito às voltas com valorações, decisões e ações. Tudo se passa como se o formalismo lógico devesse socorrer qualquer pretensão à normatividade por parte de um sujeito. A normatividade só pode ser fundada num saber puramente teórico, sem vínculo com preocupações de ordem prática. Sendo assim, toda argumentação voltada para a esfera prática da vida guardará sua relação de dependência para com um tipo de conhecimento que somente a razão teórica estaria em condições de oferecer. $\mathrm{O}$ sujeito, seja ele qual for, e esteja ele direcionado a problemas de ordem teórica ou prática, deve subordinar-se a uma legislação formal, abstraindo-se de todo interesse valorativo ${ }^{3}$.

\footnotetext{
${ }^{3}$ A esse respeito, vale lembrar que, nos Prolegômenos a uma Lógica Pura, Husserl insistira sobre o primado da ciência puramente teórica, dizendo que as disciplinas normativas, cujas leis falam do que deve ser, pressupõem uma ou mais disciplinas teóricas, ou seja, as disciplinas que têm o papel de fundamentar. Assim, se é verdade que o pensamento da normalização utiliza proposições puramente teóricas, também é verdade que as proposições normativas podem surgir de conexões Cont.
} 
Vejamos a argumentação do próprio Husserl. Se quisermos reconhecer um predicado de valor, pensa ele, é preciso apontar para o conteúdo teórico separável do dever-ser, isto é, desvinculado da normatividade expressa pelo pensamento. A esfera da normatividade terá de fundar-se numa ou mais disciplinas teóricas (HUSSERL, 2014, § 14, p. 30). Como se dá esta fundamentação? Quando visamos algo como sendo "bom", há uma intenção voltada a um conteúdo. Eis por que se pode falar de uma lógica dos atos valorativos, que conduz ao conceito de juízo normativo. Uma legislação formal preside a nossos atos mais simples de avaliação e apreciação. Já as disciplinas teóricas prescindem dessa valoração fundamental, uma vez que não dizem respeito a nada de valorativo ou ligado às nossas ações e decisões no mundo da práxis. As disciplinas teóricas são, portanto, determinadas por um interesse voltado à pura investigação das interconexões objetivas, sem nenhuma vinculação com juízos que manifestam desejo, apreciação estética, volição, etc.

O que importa é saber como, a partir de conexões teóricas do pensamento, podem surgir proposições normativas. Tudo se passa como se o interesse teórico conferisse validade à ocorrência de um estado de coisas. Por quê? Mesmo que o exercício puramente teórico se volte para a conexão objetiva, ele pode ajudar a enxergar o caráter de cientificidade das ciências normativas, ou seja, pode apontar para verdades relativas ao dever-ser. Uma disciplina teórica se beneficia de conhecimentos de verdades puramente teóri-

teóricas do pensamento. Neste caso, o ter de ser surge do ser. Formalmente, podemos dizer que a proposição "Só um A que é B é bom" transforma-se em "Um A deve ser B". Por conseguinte, o caráter de cientificidade das ciências normativas depende do conhecimento de verdades nãonormativas (cf. HUSSERL, 2014, § 16, p. 37). 
cas. No caso da ética, as normas pressupõem conhecimentos teóricos em sua base e, sendo assim, a ciência normativa tem fundamentos essencialmente teóricos (HUSSERL, 2014, § 16, p. 37).

Em suas Lições sobre ética e teoria do valor (1908-1914), Husserl se beneficia das teses de suas Investigações Lógicas para buscar construir uma ética científica por oposição ao relativismo e ao ceticismo morais. A principal tarefa era indicar as condições formais que possibilitam todo comportamento de caráter valorativo ou prático dos sujeitos humanos. Se a Lógica busca leis que circunscrevem a possível validade e sensatez das proposições cognoscitivas em geral, a Ética, por sua vez, faz ver que as "proposições" presentes no valorar e no querer também aspiram à validade. Certo, é de ética em sentido objetivo e formal que se trata, ou seja, de uma ética que não pode decidir sobre o predicado "bom" que emerge de uma situação prática. As condições formais não decidem acerca do justo e do injusto, não se pronunciam sobre a dimensão material da ética. Por isso, é fundamental estender a esfera lógica à esfera emotiva, pois o sentir, o querer e o desejar são modos intencionais que se dirigem a um conteúdo objetivo e pelos quais tomamos posição, errando e acertando. $\mathrm{O}$ agir humano será racional não porque esteja fundado em funções afetivas da consciência, mas sim sobre certas leis e teorias a priori, que funcionam como "normas racionais". Tais normas devem valer tanto para a vida teórica quanto para a esfera prática da vida (HUSSERL, 2009, § 2, p. 83) .

Se as leis normativas do pensamento encontram a contingência, isto é, relacionam-se ao momento variável da experiência concreta, marcada por conflitos e contradições que sempre pressupõem apreciações subjetivas, ou, pelo 
menos, sensibilidades humanas reais, não se pode esquecer que o agir racional implica sempre a possibilidade de uma escolha racional, válida indistintamente, determinada matematicamente. Um exemplo de correção, dada de modo axiomático, é este: "Entre os bens atingíveis, escolhe o melhor". Como se pode notar, Husserl se pergunta pelos princípios da razão prática em geral (princípios formais da razão na esfera prática), ou ainda: ele quer saber o que é o agir racional em geral, procurando, para tanto, os princípios dos quais depende o agir racional. Ora, isto culmina com o seguinte desafio: a ética formal carece de um complemento "material" que os princípios formais são incapazes de oferecer. Ela aponta para uma problemática que ultrapassa o formalismo que a sustenta, devendo buscar também:

Por si mesma não somente aquilo que se refere ao sentido universal da racionalidade segundo a forma; ao contrário, aprofundará também, segundo a matéria, as diversas ordens ou graus dos valores práticos, buscando determinar o que é racional em grau máximo, bem como as regras relativas a ele. (Husserl, 2009, § 4, p. 100).

Nesse sentido, o "conhecimento formal" é apenas uma primeira etapa de uma reflexão fenomenológica sobre a ética. Assim como a verdade, em sentido científico e filosófico, exige mais do que princípios lógicos vazios de conteúdo, a esfera da moralidade não se restringe a princípios puramente formais da razão prática. Fica, pois, em aberto a discussão sobre a tarefa humana, sobre o sujeito que quer agir eticamente, a pessoa às voltas com o dever numa situação concreta. Pois o sujeito ético é um sujeito pessoal, que vive no mundo com os outros, às voltas com valorações e ações. A esse respeito, nossa pergunta é esta: não é precisamente este sujeito que poderá realizar a atitude fenomenológica, que poderá optar pela vida dedicada à ciência? Em que me- 
dida a obra Lições sobre ética e teoria do valor já aponta para essa direção?

$\mathrm{Na}$ parte final dessas Lições, o filósofo apresenta, ao lado de sua ética formal, uma reflexão noética sobre a razão prática. Ele reconhecerá, então - e não sem embaraço -, que não se trata apenas de considerar o lado objetivo das valorações, isto é, os valores e os não-valores envolvidos, pois, "na atitude noética, estamos orientados para o próprio valor do querer evidente" (GÉRARD, 2004, p. 146). Husserl termina mostrando que o melhor, em sentido prático, não é algo puramente objetivo, mas a vontade evidente dirigida ao supostamente "melhor". Segundo Gérard, o querer ele mesmo é introduzido por Husserl no domínio prático. $\mathrm{Ou}$ seja, na perspectiva noética, a vontade se dirige tematicamente sobre si mesma. "O imperativo categórico exige a vontade do melhor" (GÉRARD, 2004, p. 146). De nossa parte, perguntamos se esta antinomia entre a abordagem objetiva e a abordagem noética não se esclarece por um motivo marcadamente ético ${ }^{4}$. Pois somente um sujeito humano concreto, pessoal, que vive num mundo circundante com os outros, estaria em condições de legitimar a validade incondicional dos princípios práticos puros. Ora, compre-

\footnotetext{
${ }^{4} \mathrm{O}$ que está em jogo não é o abandono do formalismo, nem a recusa da exigência de rigor defendida de modo magistral desde as Investigações Lógicas, mas sim saber se, mesmo fundada na razão lógica, a ética não termina sendo o sentido que confere dignidade à Ciência, à razão teórica. Certo, esta convicção só emerge alguns anos depois, sobretudo depois do desastre da Primeira Guerra. No entanto, a parte final das Lições nos leva a indagar se o referido sentido já não estava presente, de modo talvez inconsciente, antes dos acontecimentos dramáticos do início do século XX. Para Gérard (2004, p. 148), o "retorno sobre si", a "resolução radical", temas tão importantes em obras posteriores (Lógica Formal e Lógica Transcendental, por exemplo), aproximam Husserl de uma tradição que remonta a Descartes e Kant, caracterizada pela não-separação entre consciência reflexiva e consciência moral. De nossa parte, perguntamos se as análises do sujeito ético (responsável), realizadas ao final das Lições sobre ética e teoria do valor, não retomam a analogia entre razão teórica e razão prática fazendo ver que somente um sujeito pessoal e moralmente motivado estaria em condições de realizar a redução transcendental, bem como compreender o seu autêntico sentido.
} 
ender o moralmente exigido implica um juízo imparcial, objetivo, válido indistintamente para todo aquele que estivesse na mesma situação, mas o juízo em questão não pode nunca exercer-se abstratamente, isto é, fora de um contexto específico, de uma situação motivacional, do concreto da vida. Certo, a universalização depende disto: que todo aquele que estivesse em meu lugar, aprovaria a minha ação (HUSSERL, 2009,§ 19, p. 227. Itálico nosso). No entanto, sem a recorrência ao sujeito moral (responsável) inserido num mundo de valores e de situações práticas as mais diversas, os princípios formais não seriam preenchidos. $O$ problema central da ética será, portanto, anunciado já nas Lições de Ética Formal, como sendo o seguinte: a reflexão sobre o sujeito responsável às voltas com escolhas valorativas. O imperativo formal objetivo afirma: "Nos limites da esfera prática total que, a cada vez, é sua, faça o melhor entre os bens acessíveis”. No entanto, ao lado deste há também o imperativo considerado a partir do próprio querer, isto é, tomado como pergunta sobre a vontade correta. Seria a vontade, direcionada ao fim objetivamente justo, a melhor? Não deve ser também pressuposta a vontade em sentido subjetivo, ou seja, a vontade pensada a partir do próprio sujeito que valora e age?

Husserl mostra que não basta julgar com correção. Por quê? Porque é decisivo que o próprio ato de julgar seja justo (HUSSERL, 2009, § 20, p. 232). Como assim? É que o julgar racional não é apenas um juízo entre outros. Ele deve atingir a verdade não casualmente, mas sim de modo evidente. $\mathrm{O}$ sujeito deve efetivamente estar convencido daquilo que intencionou e alcançou. E quanto à ética? Não somente a justa adequação entre o visar e o visado estará em questão, mas também e, sobretudo, a aspiração a uma 
vontade justa, ou seja, a busca de se realizar um querer evidente (einsichtiges). Ao lado da correção pela qual o querer será adequado (analogia com o juízo verdadeiro), está a atitude de um sujeito que aspira a um querer justo, ou seja, de um sujeito às voltas com a Ideia de correção, com o ideal de maior clareza ou racionalidade possível. Além daquilo que é "objetivamente requerido" (das objektiv Gesollte), importa reconhecer o papel decisivo do sujeito (das Ich) que responde por suas escolhas e seus atos. (Ibid., p. 235).

\section{O IMPULSO ÉTICO DA TEORIA}

Pode-se, então, notar que a ideia de Ciência, marcada pela ênfase sobre o interesse teórico que, em princípio, não deve servir a nenhum interesse prático, recebe seu sentido da atitude ética de sujeitos concretos que a assumem, que procuram realizá-la como tarefa de vida. Por que a fundamentação propiciada pela Lógica pura foi tão importante? Para se compreender não só que a ética pode ser objetivamente fundada, mas também e, sobretudo, que a dimensão formal da razão prática é apenas uma preparação da verdadeira via que será percorrida por um sujeito que se descobriu responsável pela tarefa de autorrealização e de compromisso com a humanidade. A via da teoria se normatiza de um modo novo. A insistência inicial sobre o saber dá lugar a uma reflexão sobre a dimensão volitiva do sujeito do saber. Esta, por assim dizer, transformação prática não é uma negação do valor supremo da teoria, mas sim um novo modo de se relacionar com a tarefa de fundamentação assumida por Husserl desde os primórdios de seu pensamento. Ora, a filosofia sempre se interrogou sobre como conduzir a vida obedecendo às normas puras da razão 
(HUSSERL, 1989, p. 11). Sua tarefa, que é a de ser a mais elevada e a mais rigorosa das ciências, ou seja, realizar a aspiração da humanidade ao conhecimento puro e absoluto, só pode efetivar-se como tal porque a própria vontade estará voltada a valores puros e absolutos. O problema está em que, mesmo depois de um longo percurso histórico, "a filosofia, que teria por vocação didática exemplar contribuir para a edificação eterna da humanidade moral, se mostra incapaz do menor ensinamento que tenha um valor objetivo" (Ibid., p. 12). Ora, o que chama a atenção na proposição acima é o fato de que a busca de um fundamento sólido para a ciência (trabalho de muitas gerações de pesquisadores) se encontra ligada à "vontade consciente de aspirar a uma ciência rigorosa” (Ibid., p. 15), numa palavra, é inseparável da vocação ético-pedagógica do pensar desde Sócrates e Platão.

Temos, aqui, uma ambiguidade ou tensão, que marcará a obra do filósofo. Por um lado, a esfera da vontade assume a dianteira em relação ao saber, pois só há ciência rigorosa porque a subjetividade humana se encontra às voltas com um querer, um aspirar, um estar-voltado a algo nobre e bom (mesmo que ainda não abarcado inteiramente pelo olhar finito do homem). Mas, por outro lado, é a busca de "um ensinamento que tenha valor objetivo" que poderia fundamentar esta busca, ou ainda: é a Ciência como saber rigoroso e de princípios sólidos que se apresenta como o valor mais sublime a ser buscado. O que é mais digno, então: a aspiração, o impulso amoroso, a vontade voltada ao ideal, jamais realizado plenamente, ou o saber, a teoria, numa palavra, a evidência que se transformou em Ciência? Como pode o dependente assumir a preponderância em relação ao fundador? Como um conhecimento fundado (conheci- 
mento ético do valor) poderia dar sentido ao conhecimento que funda toda justa valoração? Como se dá a harmonização entre propósitos puramente teóricos e a dimensão prática da Ciência?

Eis, na nossa perspectiva, a ambiguidade ou tensão que atravessa o pensamento de Husserl. Isto será determinante para se compreender o recurso a uma subjetividade transcendental por parte do filósofo ${ }^{5}$. O ideal presente na filosofia desde sua mais remota idade não é relativo, mas supratemporal. Ele nos situa num horizonte de eternidade que ultrapassa, sem menosprezá-las, as preocupações relativas ao tempo presente com seus problemas imediatos. Os valores absolutos nos lançam para além do "aqui e agora" apontando para um horizonte de eternidade que será determinante para a referida obra pedagógica da humanidade vindoura. Se o ideal de ciência rigorosa deve ser reativado e renovado, não é pelo simples fato de que o ser humano se regozija com o ato de conhecer, mas sim porque, graças a este ato, podem-se compreender "as influências que exercemos sobre a história, bem como as responsabilidades morais que assumimos" (HUSSERL, 1989, p. 76). Aqui, precisamente, a fenomenologia se beneficia do encontro com filósofos da modernidade. Vejamos o exemplo de Fichte $^{6}$. Numa obra que exerceu enorme impacto nas formu-

\footnotetext{
${ }^{5}$ Sobre o impulso prático da fenomenologia transcendental, Brainard explica que foi depois da descoberta da epoché que Husserl passou usar expressões do tipo "obra de vida", "tarefa de vida" bem como de "sua missão". Não se trata de coincidência, mas de uma preocupação inerente à atitude radical da epoché, cujo efeito não é apenas teórico, uma vez que ela inaugura uma "forma ética de vida". A questão de fundo é esta: "Como posso viver uma vida racional?", ou ainda: "Como posso agir racionalmente?”. Teoria e práxis caminham, pois, juntas. Não há oposição entre elas. Mais ainda: a teoria deve servir à práxis (BRAINARD, 2007, p. 27 e ss.).

${ }^{6}$ Seria difícil, nos limites deste trabalho, explorar a relação da fenomenologia husserliana e o idealismo de Fichte. Sobre isto, muito já se escreveu. Na composição deste trabalho, consultamos: BOEHM, 1959; HART, 1995; FISETTE, 1999; SIEMEK, 2001. Para Siemek, tanto a ideia de ciência rigorosa quanto a epoché radical são propostas que aproximam Husserl de Fichte. Ao falar Cont.
} 


\section{lações das teses de Husserl, Fichte escreveu:}

Tua destinação não é simplesmente saber, mas de agir segundo teu saber. Eis o que diz a voz que, alta e forte, repercute no mais profundo de minha alma [...].Não, não é para te contemplar e te observar ociosamente, e nem para meditar sobre piedosos sentimentos, que estás aí, mas sim para a ação. É tua ação, e somente ela, que determina teu valor. (FICHTE, 1995, p. 152).

Ora, o que repugna tanto a Fichte quanto a Husserl é a renúncia à liberdade, entendida como luta pelo ordenamento moral do mundo. $\mathrm{O}$ pensamento, o eu, as idéias, etc. são momentos de forças naturais, capazes de explicar, naturalmente, as expressões da vontade e da consciência? Antes mesmo de apresentar argumentos contra esta tese, ambos adotam uma postura de recusa, de resistência e de negação, motivada por uma decisão da vontade, da afetividade. Mesmo que estejamos perdidos no labirinto da dúvida (metáfora para uma situação histórica real), podemos dispor de nossa vontade e de nosso sentimento para lutar contra as teses que põem em questão a possibilidade do pensamento e da liberdade. Ao que parece, Husserl concorda com Fichte, para quem o impulso moral é aquilo que

\footnotetext{
em "abstração" da relação aos objetos do mundo, bem como privilegiar a "reflexão" sobre aquilo que permanece depois da referida abstração, Fichte estaria se voltando ao fundamento interno do sujeito transcendental (cf. SIEMEK, 2001, p. 196). Por outro lado, é preciso lembrar que Husserl recebera enorme influência do mestre Brentano, para quem os sistemas do idealismo alemão manifestavam uma "decadência" da filosofia, ou seja, comprometiam o ideal de uma ciência rigorosa, perdendo-se em especulações (cf. FISETTE, 1999, p. 192). Não é, portanto, um retorno ingênuo a Fichte e ao idealismo alemão que está em jogo. "Antes que a filosofia fenomenológica em sentido husserliano, tivesse começado, este idealismo (alemão) só existia sob a forma de ideologia, e não sob a forma de filosofia científica" (BOEHM, p. 375). De nossa parte, pensamos ser importante destacar o aspecto ético da leitura husserliana de Fichte. O século XX encontrou-se às voltas com interpretações racistas, nacionalistas e irracionalistas do ideal germânico de cultura, ao passo que Husserl, beneficiando-se, sobretudo, dos escritos "populares" de Fichte, procurou destacar a "missão eterna e divina do povo alemão â luz da ideia pura" (BIANCHI, 1999, p. 224), isto é, da forma racional de vida. Eis por que a autêntica herança do idealismo seria a instância ética (Ibid., p. 222).
} 
há de primeiro e supremo no homem. Este princípio permite ir além do aspecto formal e objetivo da ética e da ciência, apelando para uma tarefa inesgotável de autorrealização. Não é o imperativo formal e vazio que conta, aqui, mas o impulso amoroso positivo. Mais uma vez, damos a palavra a Fichte:

O sistema da liberdade contenta meu coração, o sistema oposto o mata e aniquila. Permanecer ali, frio e morto, e assistir, unicamente como espectador, ao curso dos acontecimentos, ou como um pálido reflexo das formas fugidias - esta existência me é insuportável; eu a recuso e a e amaldiçôo. Eu quero amar, eu quero me perder sob a forma de simpatia, quero me alegrar e me entristecer (...). A vida está unicamente no amor; sem ele, há apenas a morte e o aniquilamento (FICHTE, 1995, p. 78-79).

Comentando Fichte, Husserl lembra que toda vida é aspiração, é impulso de realização, de satisfação. Mas a vida pode perder-se numa satisfação aparente, tornando-se vazia e cega. Como enfrentar este vazio e esta cegueira? A quantidade de vida será proporcional à quantidade de amor. A vida verdadeira só se desperta com a presença de um autêntico amor, isto é, um amor por algo de eterno. Ora, este movimento em direção ao bem em sentido eminente (beatitude) coincide com um imperativo moral. O ser humano sente em sua vida uma ausência de plenitude, a insuficiência da vida sensível. Ele sente a necessidade de superar esta limitação a partir de uma rígida conformidade entre agir e dever, isto é, como desejo de se submeter livremente a este imperativo (HUSSERL, 2006, p. 78). Eis por que, quando propõe retomar a ideia da filosofia como ciência rigorosa, Husserl afirma que sofremos de uma radical indigência com respeito à vida. Todo o nosso existir estaria envolvido por esta indigência, a qual nos convoca a uma atitude rigorosamente ética. 
Toda vida implica que se tome uma posição, toda tomada de posição obedece a um dever, a uma jurisprudência decidindo sobre a validade ou a não-validade, fundando-se sobre normas afirmadas que fixam o que é a validade absoluta. (HUSSERL, 1989, p. 79).

Husserl não está propondo uma atitude ingênua, que faz da obediência à norma uma espécie de remédio contra a doença de seu tempo, assim como Fichte não propunha uma defesa pura e simples à doutrina da liberdade sem obstáculos. O problema é, no caso da fenomenologia, colocar a pergunta sobre as normas e de sua realização prática num contexto filosófico e cultural caracterizado pelo questionamento da validade ideal ensinada pela fenomenologia. $\mathrm{O}$ que naturalistas e historicistas têm em comum é um poder de transformar tudo o que é vida num amontoado de fatos que, neles mesmos, são destituídos de valor e de sentido (HUSSERL, 1989, p. 79). Eis por que precisamos tomar posição, ou, para falar com Fichte, sair da posição de espectadores para assumir a condição de atores comprometidos com o pensamento e a vida. Mas, se é assim, estamos de novo diante da insuficiência do saber para realizar esta tarefa. O saber não pode, por si só, tornar-se uma resolução, um ato vontade conferindo valor ao próprio saber (FICHTE, 1995, p. 157). O saber, considerado em si mesmo, não basta. Só a decisão da vontade poderia realizar a decisão pela filosofia. Comentando Fichte ${ }^{7}$, Husserl afirma:

\footnotetext{
${ }^{7}$ Tomaremos como guia três conferências (1917) que Husserl fez sobre Fichte, em Freiburg. O interesse pelo filósofo do idealismo alemão começara logo após a publicação de Investigações Lógicas. Segundo Fisette (1999, p. 189 e ss.), trata-se de um longo período de reflexão, direcionado para o estatuto filosófico da fenomenologia, e no qual entram em cena os temas da epoché, do ego transcendental e da correlação noese-noema. Fato curioso: em 1903, Husserl dera um curso sobre a obra A destinação do homem, de Fichte. Repetirá o referido curso em 1915, bem como em 1918. Segundo Fisette, o tema será retomado pelas conferências de 1917 e 1918, texto mais substancial, intitulado Fichte e o ideal de humanidade. Sobre a importância de Fichte para a evolução da fenomenologia, o próprio Husserl escreve: "Eu estava então em condições de compreender, para além de todo romantismo conceptual, a grandeza e a eterna importância do idealismo alemão (Do ponCont.
} 
A paixão que move o seu pensamento teorético não é mera sede de saber, não é paixão por um puro interesse teorético. Fichte foi, antes, uma natureza absolutamente prática (...). Toda a sua filosofia está a serviço deste violento impulso prático (HUSSERL, 2006, p. 51).

\section{O MOTIVO ÉTICO DO IDEALISMO TRANSCENDENTAL}

No caso de Husserl, qual a decisão a ser tomada? Ela se dá sob a forma de uma redução. O que isto significa? Que é preciso resistir às desarmonias que afetam nossa relação com a realidade, vale dizer, às atitudes que impedem o reconhecimento da validade ideal. Por isso mesmo, não é uma disputa puramente teórica que está em jogo, mas uma suspensão das atitudes filosóficas (naturalismo e historicismo) que, na prática, atacam as normas que, até então, estavam em condições de orientar a vida. Reduzir a penúria atual (era a primeira década do século XX, mais precisamente, 1910) não se dá pela conquista de uma nova teoria, mas sim pela luta em favor de uma libertação em relação aos interesses temporais, decidindo-se eticamente pela busca de uma verdadeira validade objetiva de todos os domínios normativos, a militância em favor de uma ciência radical, capaz de fundamentar e oferecer um método rigoroso para a filosofia. O que motiva o filósofo a engajar-se não é o saber disponível, mas o desejo de ciência. Husserl entende que, mesmo não tendo ainda realizado o ideal de ciência rigorosa, a filosofia contou, ao longo dos séculos, com inteligências que serviram apaixonadamente ao desejo de ciência. Não é uma sabedoria procedente de uma visão de mundo em particular que nos falta, mas a colaboração

to de vista conceptual, eu estava cada vez mais direcionado a Fichte) (...). Somos dois aliados em luta contra o naturalismo contemporâneo, nosso inimigo comum" (Carta endereçada a Heinrich Rickert, de 1917 - Briefwechsel, Band V, p. 178. Apud FISETTE, 1999, p. 190). 
de pesquisadores que se beneficiam do desejo de ciência para enriquecer cada vez mais o reservatório de valores transtemporais necessários à humanidade (HUSSERL, 1989, p. 82-83).

Ora, em vez de extrair das ciências a sua forma e a sua linguagem, é a filosofia que deverá emprestá-las às ciências. Dizer que a filosofia é profunda em nada nos auxilia a superar o caos. O que é necessário e urgente são a inteligibilidade e a clareza conceituais, próprias de uma ciência rigorosa (HUSSERL, 1989, p. 83). Paradoxalmente, não é a ciência enquanto tal, isto é, uma teoria, um saber, um conhecimento alcançado etc. que se encontra em questão, mas sim um sujeito cuja vontade, mesmo numa época de crise, "é capaz de despertar a fé, a compreensão e o entusiasmo pela grandeza de um fim", bem como "encontrar as energias que podem conduzir a ele” (Ibid., p. 84). A grandeza de uma época se mede por esta disposição para lutar contra o ceticismo e o positivismo, que minam os ideais autenticamente científicos. A crença de Husserl salta à vista: qual o caminho que pode nos levar àquilo que mais nos falta, isto é, a ciência filosófica?

Devemos aderir ao radicalismo que está na natureza de toda verdadeira ciência filosófica, e que consiste em não querer aceitar nada que já tenha sido dado, que recusa todo ponto de partida transmitido pela tradição, que nos proíbe de ser fascinados por alguma autoridade, por maior que fosse, mas que, ao contrário, nos manda buscar nossos pontos de partida ao mergulharmos livremente nos próprios problemas, bem como nas exigências que deles fazem parte. (HUSSERL, 1989, p. 84)

A filosofia é a ciência dos verdadeiros começos, das origens, daquilo que é radical, daquilo que não pode ser acessado recorrendo-se as configurações históricas do pensamento, mas sim por uma visão direta, intuitiva, con- 
creta de "objetos" dados de maneira absolutamente clara. Em nenhum momento, afirma Husserl, a atitude radical de suspensão do que nos foi transmitido deve ser abandonada (HUSSERL, 1989, p. 85). Daí a pergunta: o que mantém viva esta atitude radical que suspende o suposto saber recebido? Acompanhamos, aqui, a argumentação de Brainard. A redução purifica a consciência de todo tipo de crenças. A consciência se torna solitária e pura. No entanto, mesmo depois de suspender as crenças, o eu precisa acreditar na razão. O prosseguimento de sua tarefa racional depende disto. Por conseguinte, a redução deve propiciar uma modificação radical da consciência. $\mathrm{O}$ efeito prático da epoché consiste nisto: o "eu velho" sai de cena para dar lugar uma nova forma de vida. Tem início uma forma radicalmente nova de existência: uma vida de autorreflexão, de auto-explicitação, de autorresponsabilidade. A redução nos convoca à ideia de um ser humano autêntico e "racional". Trata-se da vontade de inaugurar uma vida autêntica, que por sua vez implica a vontade de ser tornar um novo homem (cf. BRAINARD, 2007, p. 27-8).

Eis por que pensamos ser legítimo perguntar se a própria subjetividade transcendental, isto é, a suposta passagem de uma perspectiva realista para a idealista não se dá, no caso de Husserl, em decorrência de um motivo ético, caracterizado como ato da vontade que confere sentido ao saber. Como assim? Na perspectiva de Fichte nosso saber não se funda em si mesmo, mas sim sobre nossas tendências, nossas inclinações. Não porque sejamos dominados pelas forças que nos habitam, mas sim porque é a partir dessas forças que, curiosamente, podemos nos formar a nós mesmos. Não somos duas realidades (ou substâncias) convivendo ou buscando conviver, e sim uma unidade! O conhecer 
não se separa das tendências que constituem a nossa identidade. $\mathrm{O}$ desafio é despertar para este conhecimento de si, como tomada de consciência de que nós nos criamos a nós mesmos. Não há necessidade cega, nem mesmo um puro acaso, que poderiam fazer do eu um joguete. Ele é responsável por esta tarefa de autodeterminação, de autoformação, de desenvolvimento e realização da ciência. Mas, nesta tarefa, é preciso atentar para importância do dever, isto é, para a pergunta pelo que devo fazer. Reconhecer que o conhecimento de meu dever é o fim mesmo do conhecimento, eis para Fichte a tarefa incontornável da reflexão (FICHTE, 1995 , p. 160 ss.).

Para Husserl seria equivocado ver na atitude Fichte a expressão de um moralista, ou de um pastor-filósofo, pois suas intuições ético-religiosas têm uma ancoragem teórica. O que está em questão não é, portanto, um abandono da teoria em benefício da prática, mas sim a compreensão de que é a própria consciência moral que nos comanda uma realização da teoria. Assim, podemos notar que os argumentos lançados por Husserl em sua obra A filosofia como ciência rigorosa são como que aclarados eticamente, alguns anos depois, com a ajuda de Fichte. Não basta dizer apenas que a força moral impulsionando a filosofia pode ser encontrada nos grandes espíritos do passado (Platão, por exemplo). É preciso mais: reconhecer que são necessários um longo percurso e muitas épocas para que a ciência rigorosamente fundada suba seus degraus. Eis a meta ainda não atingida e, por isso mesmo, a ser retomada. Para tal, não basta fazer ciência, mas dar-se conta da força moral que se manifestou em grandes espíritos e que comandou, historicamente, esta ascensão. Não importa, no caso, que a intuição desses espíritos tenha carecido de amadurecimento 
teórico, mas sim entender que tal amadurecimento depende do impulso e do desenvolvimento que decorrem de suas intuições. Ora, o que os próprios homens de ciência esquecem é isto:

Nas ciências da natureza o método e a teoria rigorosos não existiram de uma hora para outra, nem foram inventados por algum cientista habilidoso (...). Trata-se antes do resultado de uma luta fatigante, de milhares de anos, conduzida por espíritos geniais, os quais, guiados por grandes intuições e inventando, com criatividade, experimentos sempre novos para chegar a dominá-los, trabalharam para a futura ciência rigorosa e, sobretudo, tornaram-na possivel enquanto tal. (HUSSERL, 2006, p. 52)

O leitor já deverá ter identificado a dificuldade. Por um lado, o recurso à suspensão de todo o recebido pela tradição, de toda teoria e de todo o sistema de pensamento que nos vem do passado e do presente. Tudo isto deve ser posto entre parênteses pela epoché. Mas, de outro lado, é preciso apropriar-se do conteúdo espiritual dos grandes sistemas filosóficos, é forçoso retomar as intuições já alcançadas pelos grandes espíritos. Depois da suspensão das crenças, resta ainda uma crença: aquela que se compreende como confiança incondicionada na razão. Estamos diante de uma contradição no pensamento de Husserl? Ora, o ensinamento de Fichte parece ir ao encontro do que marcará a evolução da fenomenologia transcendental para o "idealismo": suspender as teses supõe um ato da vontade que nos faz ver as intuições de "conhecimentos" que não dizem respeito à mera curiosidade teórica. Tomar (metodicamente) a existência do que está fora de nós mesmos a partir dos atos da consciência não é reduzir tudo a meras representações de uma subjetividade, mas sim acordar para o fato de que a consciência não é nunca apenas um evento casual no interior do mundo. 
Para Fichte, assim como para Husserl, não é o "objeto" que decide. É fundamental interrogar sobre o ato de se colocar em relação representações e coisas. Na Doutrina da Ciência de Fichte, não se toma posição sobre a existência da coisa (do mundo, de Deus, da alma, dos objetos, etc.). A questão sobre a existência da coisa é desqualificada, embora o acordo entre os atos e os seus correlatos permaneça mantido. Qual é a necessidade deste ato? Não é em função de uma teoria do mundo objetivo. O que importa é refletir sobre os atos que tornam as teorias possíveis. É preciso se voltar para o sujeito desses atos (FICHTE, 2000, § 1, p. 70). Não será por uma recepção deste modelo que Husserl irá afirmar, mais de cem anos depois, que a objetividade provém da efetuação subjetiva, e que sem o esclarecimento disto a objetividade lógica, ela também, fica carente de claridade? (HUSSERL, 1996, § 8, p. 50). Mas o que tem isto com o motivo ético? Para Husserl, o amor à verdade, presente no interesse teórico, é um interesse direcionado a um fim, a um interesse prático. Por quê? Porque o que se quer é, precisamente, realizar a verdade. O que nos guia na busca de uma ciência rigorosa é a unidade de um fim prático e de um sistema de fins (HUSSERL, 2009a, § 3, p. 17).

O idealismo transcendental não pode prescindir de um sujeito que tomou consciência dos fins que deveriam ser, que deveriam ser perseguidos, que merecem ser buscados (HUSSERL, 2009a, § 1, p. 6). É a vida total do ser humano, sua destinação (Fichte), que está em questão. Como pode esta vida ser regulada de modo absolutamente unitário, isto é, ser movida pela razão prática? "Submeter a si tudo o que é desprovido de razão, dominá-lo livremente e segundo a sua própria lei: este é o derradeiro fim último do homem" (FICHTE, 2014, p. 27). É preciso responder pelo ordenamento racio- 
nal do mundo. É este, com efeito, o princípio da própria realidade do mundo. $\mathrm{O}$ recurso ao eu permite mostrar não a realidade enquanto tal, separada de nós, desvinculada da subjetividade humana. Tal mundo, mesmo não sendo uma mera criação do eu, é constituído nele. Para Fichte, explica Husserl, "o eu é sempre dominado pelo impulso racional, pelo impulso à realização desta ideia normativa de um ordenamento moral do mundo" (2006, p. 65). Impulso este que, em Husserl, será direcionado à filosofia como ideia. É preciso colocar em prática a ideia de filosofia. A fenomenologia, como ciência rigorosa, requer o acolhimento de um chamado, o ato de assumir uma responsabilidade. Para buscar realizar essa ideia, é preciso colocar a própria vida em risco. $\mathrm{O}$ giro transcendental é o emblema da luta para atingir a ideia de filosofia, para reativá-la. Atitude radical cuja meta é manter unidas teoria e práxis. Mas onde encontrar as forças necessárias para enfrentar tal desafio? "Aquele que é capaz de despertar a fé, a compreensão e o entusiasmo pela grandeza de um fim" (HUSSERL, 1989, p. 83) não terá nenhuma dificuldade para encontrar essas forças.

Abstract: The paper aims to investigate the ethical motive which led Husserl to defend the transcendental subjectivity. The central thesis is that phenomenological attitude is more than a pure methodical and theoretical approach on human subjectivity. Husserlian's use of the transcendental ego has a practical purpose. Considering that phenomenology always begins by the suspension of the natural attitude, the possibility of this suspension implicates a paradox: the ego must preserve his belief in reason and science in order to carry out the neutralization of its beliefs concerning natural attitude. This belief is crucial in order to understand the ethical meaning of the transcendental reduction which is the beginning of an entirely new form of life.

Keywords: Ethics, phenomenology, transcendental subjectivity, reduction. 


\section{REFERÊNCIAS}

BIANCHI, I.A. Ética Husserliana. Studio sui manoscritti inediti degli anni 1920-1934, Milano: Franco Angeli, 1999.

BOEHM, R. Husserl et l'idéalisme classique. In: Revue philosophique de Louvain, tome 57, (1959), p. 351-396.

BRAINARD, M. «For a New World»: On the practical impulse of Husserlian theory .In: Husserl Stud, 2007, p. $17-31$.

GÉRARD, V. L'analogie entre l'éthique formelle et la logique formelle chez Husserl.In: CENTI, B./Gigliotti,G. Fenomenologia della ragion pratica. L'etica di Edmund Husserl, Napoli: Bibliopolis, 2004 (p. 117-150).

FICHTE, J.G. La destination de l'homme. Trad. JeanChristophe Goddard; Paris: Flammarion, 1995.

. Doctrine de la science. Nova methodo. Trad. Isa-

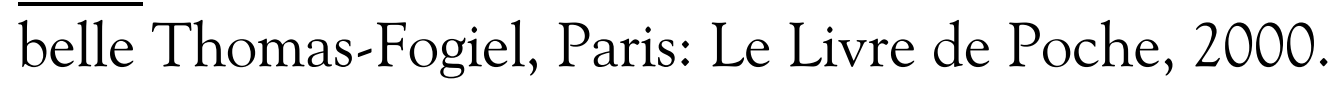

. O destino do erudito. Trad. Ricardo Barbosa, São Paulo: Hedra, 2014.

FISETTE, D. Husserl et Fichte: Remarques sur l'apport de l'idéalisme dans le développement de la phénoménologie.In: Symposium, III, 2 (1999), p. 185-207.

HART, J.G. Husserl and Fichte: With special regard to Husserl's lectures on «Fichte's ideal of humanity».In: Husserl Studies, 12 (1995), p. 135-163.

HUSSERL, E. La philosophie comme science rigoureuse. 
Trad. Marc B. De Launay; Paris: PUF, 1989.

. Fichte e l'ideale di umanità. Tre lezione. Trad. Francesca Rocci; Pisa: Edizioni ETS, 2006.

. Logique formelle et logique transcendantale. Trad. Suzanne Bachelard, Paris: PUF, 1996.

.. Leçons sur l'éthique et la théorie de la valeur. Trad. Philippe Ducat, Patrick Lang e Carlos Lobo, Paris: PUF, 2009.

. Introduzione all'etica. Trad. Nicola Zippel, RomaBari: Laterza, 2009 a.

. Investigações Lógicas (Prolegômenos à Lógica Pura). Trad. Diogo Ferrer, Rio de Janeiro: Forense, 2014.

SIEMEK, M.J. Husserl e a herança da filosofia transcendental. In: Síntese - Revista de Filosofia, v. 28, n. 91 (2001), p. 189-202. 